\title{
Ultrafine Particle Deposition and Clearance in the Healthy and Obstructed Lung
}

\author{
James S. Brown, Kirby L. Zeman, and William D. Bennett \\ Center for Environmental Medicine and Lung Biology, University of North Carolina at Chapel Hill, Chapel Hill, North Carolina
}

\begin{abstract}
Numerous epidemiologic studies have shown associations between exposure to particulate air pollution and acute increases in morbidity and mortality, particularly in persons with chronic obstructive pulmonary disease. The dosimetry of ultrafine particles in the human lung is poorly characterized. We studied the deposition and clearance of an ultrafine technetium-99m-labeled aerosol in $10 \mathrm{pa}$ tients with chronic obstructive pulmonary disease and in 9 healthy subjects. Particle retention was followed for $\mathbf{2}$ hours after inhalation and again at 24 hours by $\gamma$ scintigraphy. Central-to-peripheral ratios indexed airway deposition. Particle accumulation in the liver was examined by quantifying activity below the right lung. The dose rate for an aerosol exposure of $10 \mu \mathrm{g} / \mathrm{m}^{3}$ was calculated. Patients had a significantly greater dose rate than healthy subjects $(2.9 \pm$ 1.0 versus $1.9 \pm 0.4 \mu \mathrm{g} / \mathrm{h}, \mathrm{p}=0.02)$. Central-to-peripheral ratios were slightly greater in patients than in healthy subjects (1.11 \pm 0.10 versus $1.01 \pm 0.11, p=0.05$ ). Clearance did not statistically differ between health and disease. On average, 24-hour retention was $85 \pm 8 \%$ (corrected for isotope dissolution). No accumulation in the liver's vicinity was observed. Data suggest that relative to healthy subjects, patients with moderate-to-severe airways obstruction receive an increased dose from ultrafine particle exposure.
\end{abstract}

Keywords: aerosols; mucociliary clearance; chronic obstructive pulmonary disease

Epidemiologic studies have shown consistent associations between the exposure to particulate air pollution and acute increases in morbidity and mortality rates, especially for persons with obstructive lung and cardiovascular diseases $(1,2)$. Some toxicologic studies have implicated ultrafine particles (less than $0.1 \mu \mathrm{m}$ in diameter), which by count constitute the majority of urban particulate air pollution, as having increased toxicity relative to larger particles composed of the same materials $(3,4)$. Epithelial uptake of ultrafine particles may occur in as little as 1 hour after exposure and may cause damage to epithelial cells, pulmonary edema, and eventually fibrosis $(4,5)$. An increased probability of death for persons with cardiovascular diseases has been proposed as a result of an inflammatory response caused by ultrafine particle overloading and subsequently increased blood coagulability (6).

(Received in original form May 6, 2002; accepted in final form July 26, 2002)

Supported by the United States Environmental Protection Agency cooperative agreement (CR824915) and the Center for Environmental Medicine and Lung Biology, University of North Carolina at Chapel Hill.

Although the research described in this article has been supported by the United States Environmental Protection Agency, it has not been subjected to agency review and therefore does not necessarily reflect the views of the agency, and no official endorsement should be inferred. Mention of trade names or commercial products does not constitute endorsement or recommendation for use.

Correspondence and requests for reprints should be addressed to James S. Brown, Ph.D., Center for Environmental Medicine and Lung Biology, University of North Carolina at Chapel Hill, 104 Mason Farm Road, CB\# 7310, Chapel Hill, NC 27599. 7310. E-mail: brown.james@epa.gov

Am J Respir Crit Care Med Vol 166. pp 1240-1247, 2002

Originally Published in Press as DOI: 10.1164/rccm.200205-3990C on August 1, 2002 Internet address: www.atsjournals.org
Increased plasma viscosity has been found in association with elevated sulfur dioxide and particulate levels (7). A recent study has also shown an association between ultrafine particulate exposure and decreased peak expiratory flows in patients with asthma (8). Ultrafine aerosol exposure may contribute to the increase in morbidity and mortality observed by epidemiologic studies.

A fair amount of data on the deposition of ultrafine particles in healthy volunteers is available (9-13). However, ultrafine deposition data for the diseased lung are limited to five chronic obstructive pulmonary disease (COPD) patients and three restrictive lung disease patients studied by Anderson and colleagues (11). Data for ultrafine particle clearance from the human lung are far more limited. Roth and colleagues (14) reported a total lung clearance of $7 \%$ over a 24-hour period for an 18-nm (count modal diameter) indium oxide aerosol in three healthy subjects. To the best of our knowledge, no other ultrafine particle clearance data in humans are reported in the literature.

A number of studies have been published on the deposition and/or clearance of agglomeration-mode carbon particles, Technegas. The primary particles that compose Technegas are in the range of 5-20 nm $(15,16)$. However, before inhalation, these primary particles coagulate into aggregates with a median diameter in the range of 100 to $160 \mathrm{~nm}$ (1517). Technegas particles can be as large as $225 \mathrm{~nm}$ if the time between aerosol generation and inhalation increases to 8.5 minutes (16). Although Technegas is frequently referred to as an ultrafine aerosol (18-20), inferences based on these studies with regard to the behavior of ultrafine particles in the respiratory tract should be made with caution.

From a dosimetric viewpoint, the distinction between an inhaled aerosol with a median diameter of $20 \mathrm{~nm}$ versus one of 100 or $200 \mathrm{~nm}$ is very important. Particle size affects the site and amount of particle deposition as well as subsequent clearance. Considering a sedentary breathing pattern (tidal volume $[\mathrm{VT}]=500 \mathrm{ml}$, frequency $[\mathrm{f}]=15 \mathrm{~min}^{-1}$ ), the total deposition of $20-\mathrm{nm}$ particles is 2.7 times greater than predicted for $100-\mathrm{nm}$ particles and is 4.3 times greater than predicted for 200-nm particles (21). Moreover, the site of deposition in the lung shifts proximally with decreasing particles size below $100 \mathrm{~nm}$ (13). This proximal shift in deposition affects not only the tissue dose to the airways but also the subsequent mucociliary clearance rate (i.e., a shorter path length for clearance from the lung).

The purpose of our study was to characterize the deposition and clearance of a technetium-99m-labeled ultrafine aerosol in patients with COPD and healthy age-matched volunteers. Ten patients with moderate to severe COPD (six men and four women; 45-70 years old) and nine healthy nonsmokers (three men and six women; 40-67 years old) participated in this study. Lung function, that is, spirometry, plethysmography, and diffusing capacity (MedGraphics, St. Paul, MN, and SensorMedics, Yorba Linda, CA) were measured in each subject. Single-breath nitrogen washout phase III slope and multibreath xenon whole-lung washout rate 


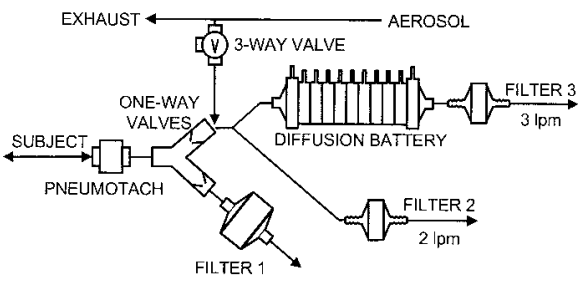

Figure 1. The aerosol delivery system. Once the subject began breathing through the pneumotach, a three-way valve was switched to supply aerosol rather than room air. One-way valves routed aerosol to and from the subject. Exhaled aerosol was captured on Filter 1, a lowresistance filter (BB-5OT; Pall Biomedical). The aerosol's specific activity and in vitro isotope leaching from particles were based on analysis of Filter 2, a glass fiber filter (Type A/E; Gelman Sciences, Ann Arbor, MI). The aerosol's activity median diameter was determined using a diffusion battery (25) and a glass fiber filter, Filter 3.

were also determined (22). This study was approved by the Committee on the Protection of the Rights of Human Subjects (School of Medicine, University of North Carolina at Chapel Hill, NC). Before participating in this study, all subjects were informed of the study's associated risks and signed a statement of informed consent.

\section{METHODS}

\section{Aerosol Inhalation}

We have previously described the generation and characterization of the experimental technetium-99m-labeled ultrafine carbon aerosol (23). To control coagulation, aerosol was continuously generated and diluted with filtered air.

The subjects inhaled aerosol at their natural breathing pattern (24) until approximately $25 \mu \mathrm{Ci}$ was deposited in the lung. Activity was monitored by a single crystal (NaI) scintillation detector (ND detector, Model LMS-44; Nuclear Data Inc., Smyrna, GA) against the back. Figure 1 illustrates the aerosol delivery system and sampling locations. The aerosol's count median diameter (CMD) was measured by a Scanning Mobility Particle Sizer (TSI Incorporated, St. Paul, MN) for 10 subjects. The aerosol's activity median diameter (AMD), and leaching characteristics were determined for all subjects $(23,25)$.

Before aerosol inhalation, a xenon- 133 equilibrium scan was acquired by a large field of view $\gamma$ camera (Elscint Apex 415, Haifa, Israel) (26). After aerosol inhalation, retention scans (2 minutes per scan) were recorded for 2 hours by the $\gamma$ camera. At approximately 24 hours after inhalation, subjects returned for a 30 -minute retention scan.

\section{Data Analysis}

The deposition fraction (DF) of aerosol in the lung was defined as

$$
\mathrm{DF}=1-\frac{\mathrm{A}_{\mathrm{Ex}}}{\mathrm{A}_{\mathrm{In}}}
$$

where $A_{E x}$ and $A_{I n}$ are exhaled and inhaled activity, respectively. $A_{E x}$ was the ND detector measured counts on Filter 1 (Figure 1). The filter was centered at 1 foot from the detector face and counts accumulated for 30 seconds. This method was also used for diffusion battery stages, other filters, and isotope leaching measurements. $\mathrm{A}_{\text {In }}$ was the product of total inspired volume during aerosol inhalation and the aerosol's specific activity. Total inspired volume was computed as the product of average inspiratory flow, aerosol inhalation time, and fraction of breathing devoted to inhalation. Aerosol specific activity was the counts on Filter 2 (Figure 1) divided by volume sampled through this filter. DF data were corrected for a VT-dependent bias (APPENDIX). The dose rate $\left(D_{\text {rate }}\right)$ for sedentary breathing was calculated for each subject:

$$
\mathrm{D}_{\text {rate }}=\mathrm{DF} \cdot \mathrm{V}_{\min } \cdot \mathrm{C}
$$

where $\mathrm{V}_{\min }$ is minute ventilation and $\mathrm{C}$ is an assumed exposure concen-

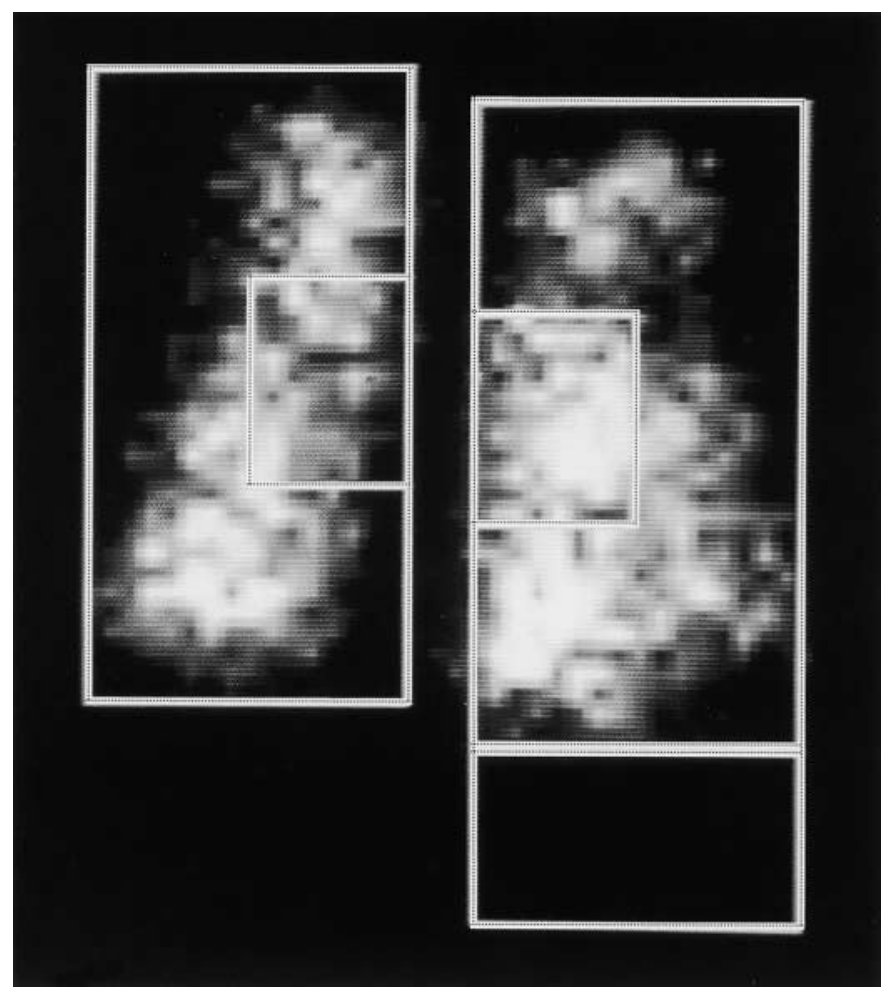

Figure 2. An initial deposition scan for a COPD patient (61-year-old female, $31 \%$ predicted $\mathrm{FEV}_{1}$ ) illustrating whole lung, central, and the liver ROI. The whole-lung ROls for each lung were set at $20 \%$ of the peak xenon equilibrium counts. Central ROls, with dimensions equal to half the lung's width and one-third its height, were positioned on the interior boundary of the lung, centered by height. A liver ROI was established immediately below the right lung with dimensions of one third the lung's height and its full width. Despite severe COPD, qualitatively, the pattern of deposition appears fairly uniform and quantitatively, the patient's $C / P_{0}$ ratio is still only 1.17 .

tration of $10 \mu \mathrm{g} / \mathrm{m}^{3}$. This exposure concentration was used because epidemiologic studies commonly express health risk from ambient particulate exposure in $10 \mu \mathrm{g} / \mathrm{m}^{3}$ increments (2).

\section{Scintigraphic Analysis}

Figure 2 illustrates regions of interest (ROIs). Pulmonary particle retention was determined from combined counts of the left and right wholelung ROIs (background/decay corrected). Twenty-four-hour retention was "corrected" for isotope dissolution by dividing by one minus the fraction of activity leached from particles. Central-to-peripheral $(\mathrm{C} / \mathrm{P})$ ratios index large airways deposition (27-29) and were determined for the initial retention scan $\left(\mathrm{C} / \mathrm{P}_{0}\right)$ and 24-hour retention scan $\left(\mathrm{C} / \mathrm{P}_{24}\right) . \mathrm{C} /$ $\mathrm{P}$ ratios were computed as the fraction of aerosol deposited in central regions relative to peripheral regions and normalized to volume using the same regions with an xenon equilibrium scan (26).

Two statistical methods tested differences in clearance rates between healthy subjects and COPD patients. At 1,2, and 24 hours after inhalation, differences were tested using a two-tailed $t$ test. Differences in retention curves through 2 hours after inhalation were tested by a linear mixed-effects model $(30,31)$. The logarithm of retention was used in this model fit by S-plus 2000 Professional (MathSoft Inc., Seattle, WA).

Activity in the liver was quantified through 2 hours after inhalation for comparison with the results of Nemmar and colleagues (20). Liver ROI counts (background/decay corrected) were normalized by the sum of counts (background corrected) in the whole-lung ROIs and liver ROI from the initial retention scan. 


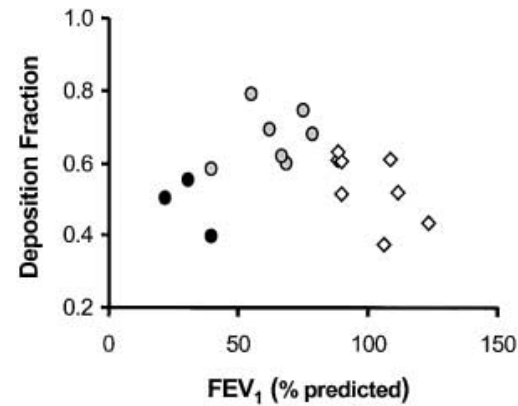

Figure 3. The particle DF in each subject versus pulmonary function. The DF in seven bronchitic patients (gray circles) was significantly $(p<0.04)$ greater than in the nine healthy subjects (open diamonds) and the three emphysemic patients (black circles) (see Table 2).

\section{RESULTS}

Unless otherwise stated, data provided in the text are mean \pm $\mathrm{SD}$, and data illustrated in Figures 5 and 6 are mean \pm SEM. Between-group differences were tested using Student's $t$ test (two-tailed) with the exception of the mixed-effects model used to test for differences in particle retention. Pearson correlation coefficients were used to determine associations between variables. The experimental aerosol had an AMD of $61 \pm 4 \mathrm{~nm}$ and a geometric standard deviation $\left(\sigma_{\mathrm{g}}\right)$ of $2.1 \pm 0.1$. The aerosol's CMD was $33 \pm 2 \mathrm{~nm}$ with a $\sigma_{\mathrm{g}}$ of $1.7 \pm 0.03$. Primary particles that aggregated to form the experimental aerosol had a CMD of approximately $22 \mathrm{~nm}$ (23). There were no statistically significant differences in aerosol characteristics between groups. Anthropometric and baseline pulmonary function data are given in Table 1. Single-breath nitrogen washout was not conducted on one COPD patient because of equipment failure. The COPD patients were subdivided into a bronchitic and an emphysemic group, with the latter having less than $60 \%$ predicted carbon monoxide diffusing capacity and diffusing capacity normalized to lung volume. Significant differences between the COPD patient subgroups were observed for pulmonary function data (Table 1), DF data (Table 2), and spontaneous breathing patterns (Table 2).

Inhaled aerosol deposition (total and regional) and breathing patterns during the aerosol inhalations are provided in Table 2. The DF datum for one healthy subject was discarded because of valve leaks. The aerosol DF in the bronchitic patients was significantly greater than the DF in either the emphysemic patients or the healthy subjects. During aerosol inhalations, the bronchitic group had a significantly longer breathing period than both the emphysemic group and the healthy subjects. These bronchitic patients also breathed aerosol at a VT that was significantly greater than the healthy subjects and tended to be greater than the emphysemic group. The VT-dependent DF correction (described in the METHODS) increased with decreasing $\mathrm{V}_{\mathrm{T}}$; hence, the effect of the DF correction should have been to bias the observed increase in DF for the bronchitic patients toward the

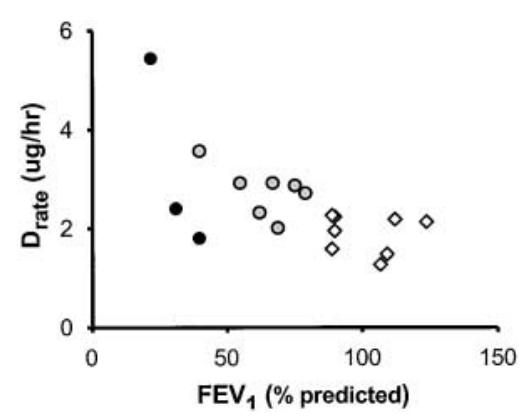

Figure 4. $\mathrm{D}_{\text {rate }}$ in each subject versus pulmonary function. Across all subjects $(\mathrm{n}=$ $18), D_{\text {rate }}$ and lung function were significantly correlated $(r=-0.64, p=0.004)$. Healthy subjects $=$ open diamonds; emphysemic patients = black circles; bronchitic patients = gray circles.

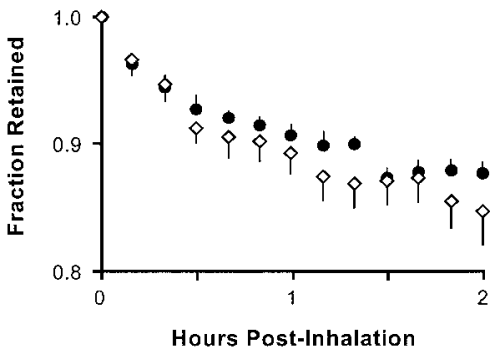

Figure 5. Pulmonary particle retention over the 2-hour period immediately after inhalation in 10 COPD patients (closed circles) and 9 healthy subjects (open diamonds). Values are mean data, and bars reflect SEs. Note that the ordinate begins at $80 \%$ retention. Although not statistically significant, the COPD patients tended to have slower clearance than the healthy subjects.

null. No significant correlations were observed between DF and breathing pattern within any group (e.g., bronchitic subjects) nor across groups (e.g., combined data for bronchitic and healthy subjects). DF data as a function of forced expiratory volumes are illustrated in Figure 3. In healthy subjects $(\mathrm{n}=8)$, DF was significantly correlated with $\mathrm{FEF}_{25-75}(\mathrm{r}=-0.73, \mathrm{p}=0.04)$. In the COPD patients $(n=10)$, because of the emphysemic data, there was a positive correlation between DF and both percentage predicted $\mathrm{FEV}_{1}(\mathrm{r}=0.65, \mathrm{p}=0.04)$ and percentage predicted diffusing capacity normalized to lung volume $(\mathrm{r}=0.80, \mathrm{p}=$ 0.005 ). Significant negative correlations were again observed for the combined dataset $(n=15)$ of the bronchitic group and healthy subjects between DF and both $\mathrm{FEF}_{25-75}(\mathrm{r}=-0.77, \mathrm{p}=$ $0.001)$ and percentage predicted $\mathrm{FEV}_{1}(\mathrm{r}=-0.65, \mathrm{p}=0.009)$. Across all subjects, DF was not correlated with these variables. To better elucidate the driving factors affecting DF, a forward stepwise regression was performed for all subjects $(n=18)$, which included all pulmonary function data in Table 1, aerosol breathing pattern (Table 2), and lung volumes (FRC, RV, TLC, FRC/TLC, RV/TLC). In Table 3, the results of this analysis show that DF increases with the percentage predicted diffusing capacity normalized to lung volume $(p=0.001)$ and decreases with $\mathrm{FEF}_{25-75}(\mathrm{p}<0.001)$.

The $\mathrm{D}_{\text {rate }}$ of the aerosol (Table 2), assuming an exposure concentration of $10 \mu \mathrm{g} / \mathrm{m}^{3}$, was significantly increased in the COPD patients $(\mathrm{p}=0.02)$ and the bronchitic patients $(\mathrm{p}=$ 0.002 ) relative to healthy subjects. The $D_{\text {rate }}$ for the emphysemic patients was not significantly different from that of the bronchitic patients. Figure 4 illustrates $D_{\text {rate }}$ as a function of percentage predicted $\mathrm{FEV}_{1}$. For combined dataset $(\mathrm{n}=15)$ of the bronchitic group and healthy subjects, $D_{\text {rate }}$ was correlated with percentage predicted $\mathrm{FEV}_{1}(\mathrm{r}=-0.74, \mathrm{p}=0.002)$ and to a lesser extent with $\mathrm{FEF}_{25-75}(\mathrm{r}=-0.61, \mathrm{p}=0.02)$. Similarly, across all subjects $(\mathrm{n}=18), \mathrm{D}_{\text {rate }}$ was correlated with both percentage predicted $\mathrm{FEV}_{1}(\mathrm{r}=-0.64, \mathrm{p}=0.004)$ and $\mathrm{FEF}_{25-75}(\mathrm{r}=-0.48, \mathrm{p}=$ $0.04)$. A forward stepwise regression was performed to elucidate

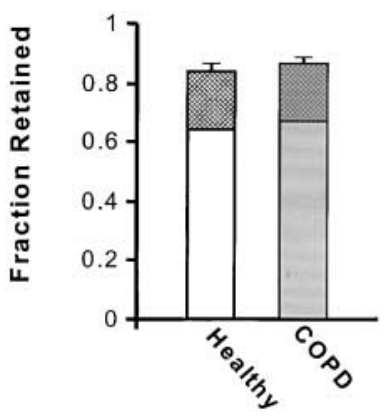

Figure 6. Pulmonary particle retention by disease status at 24 hours after inhalation in 10 COPD patients and 9 healthy subjects. Values are mean data, and bars reflect SEs. The hatched area indicates a correction for $23 \pm 4 \%$ isotope leaching from particles determined by in vitro measurements. 
TABLE 1. GROUP MEAN AGE AND PULMONARY FUNCTION DATA

\begin{tabular}{|c|c|c|c|c|}
\hline & \multirow[b]{2}{*}{$\begin{array}{l}\text { Healthy Subjects } \\
\qquad(3 M, 6 F)\end{array}$} & \multicolumn{3}{|c|}{ COPD Patients } \\
\hline & & $\begin{array}{l}\text { All Patients } \\
(7 \mathrm{M}, 3 \mathrm{~F})\end{array}$ & $\begin{array}{c}\text { Bronchitic Patients } \\
\qquad(5 \mathrm{M}, 2 \mathrm{~F})\end{array}$ & $\begin{array}{c}\text { Emphysemic Patients } \\
\qquad(2 \mathrm{M}, 1 \mathrm{~F})\end{array}$ \\
\hline Age, yr & $53 \pm 11$ & $61 \pm 6.9^{*}$ & $60 \pm 7.5$ & $64 \pm 5.2$ \\
\hline $\mathrm{FEF}_{25-75}$, Ips & $2.82 \pm 0.90$ & $0.50 \pm 0.23^{*}$ & $0.57 \pm 0.24^{*}$ & $0.34 \pm 0.02^{*}$ \\
\hline $\mathrm{FEV}_{1}, \%$ predicted & $104 \pm 16$ & $54 \pm 20^{*}$ & $64 \pm 13^{*}$ & $31 \pm 9.0^{* \dagger}$ \\
\hline $\mathrm{FEV}_{1} / \mathrm{FVC}, \%$ & $79 \pm 3.1$ & $44 \pm 13^{*}$ & $50 \pm 10^{*}$ & $29 \pm 6.4^{\star \dagger}$ \\
\hline Raw, $\mathrm{cm} \mathrm{H} \mathrm{H}_{2} \mathrm{O} / \mathrm{lps}$ & $1.26 \pm 0.42$ & $2.52 \pm 0.91^{*}$ & $2.16 \pm 0.63^{*}$ & $3.36 \pm 1.04^{\star \dagger}$ \\
\hline sRaw, $\mathrm{cm} \mathrm{H}_{2} \mathrm{O} \mathrm{s}$ & $4.83 \pm 1.69$ & $16.8 \pm 14.8^{*}$ & $10.3 \pm 3.65^{*}$ & $32.0 \pm 21.1^{* \dagger}$ \\
\hline $\mathrm{D}_{\mathrm{CO}}, \mathrm{ml} \mathrm{CO} / \mathrm{min} / \mathrm{mm} \mathrm{Hg}$ & $23 \pm 3.7$ & $17 \pm 7.0^{*}$ & $20 \pm 5.6$ & $9.6 \pm 1.8^{* \dagger}$ \\
\hline $\mathrm{DL}_{\mathrm{CO}}, \%$ predicted & $112 \pm 9.1$ & $72 \pm 23^{*}$ & $84 \pm 13^{*}$ & $43 \pm 4.5^{\star \dagger}$ \\
\hline $\mathrm{DL}_{\mathrm{CO}} / \mathrm{V}_{\mathrm{A}}, \mathrm{ml} \mathrm{CO} / \mathrm{min} / \mathrm{mm} \mathrm{Hg} / \mathrm{L}$ & $4.47 \pm 0.81$ & $3.03 \pm 1.12^{*}$ & $3.60 \pm 0.68^{*}$ & $1.68 \pm 0.56^{* \dagger}$ \\
\hline DLco/VA, $\%$ predicted & $109 \pm 17$ & $78 \pm 27^{*}$ & $92 \pm 15^{\ddagger}$ & $44 \pm 14^{* \dagger}$ \\
\hline$\Delta \mathrm{N}_{2}, \% / \mathrm{L}$ & $1.85 \pm 0.82$ & $8.88 \pm 5.26^{*}$ & $5.69 \pm 2.60^{*}$ & $15.3 \pm 1.5^{\star \dagger}$ \\
\hline $\mathrm{Xe}_{\mathrm{w},} \min ^{-1}$ & $-1.00 \pm 0.21$ & $-0.75 \pm 0.28^{*}$ & $-0.88 \pm 0.19$ & $-0.42 \pm 0.10^{* \dagger}$ \\
\hline
\end{tabular}

Definition of abbreviations: COPD = chronic obstructive pulmonary disease; $\mathrm{DL}_{\mathrm{co}}=$ carbon monoxide diffusing capacity; $\mathrm{D} \mathrm{L}_{\mathrm{co}} /$ $\mathrm{V}_{\mathrm{A}}=$ diffusing capacity normalized to lung volume; $\Delta \mathrm{N}_{2}=$ single breath nitrogen washout's phase III slope; Raw = airway resistance; $\mathrm{sRaw}=$ specific airway resistance; $\mathrm{Xe}_{\mathrm{w}}=$ multibreath xenon washout rate.

* Significantly different from healthy subjects $(p<0.05)$.

† Significantly different from bronchitic subjects $(p<0.01)$.

* Marginally significant difference from healthy subjects $(p=0.058)$.

Values are means $\pm S D$. Predictive equations for $\mathrm{FEV}_{1}$ are from Knudson and colleagues (32). Predictive equations for $\mathrm{LL}_{\mathrm{CO}}$ and $\mathrm{DL}_{\mathrm{CO}} / \mathrm{V}_{\mathrm{A}}$ are from Burrows and associates (33).

factors affecting $\mathrm{D}_{\text {rate }}$ in the same manner as described for DF. In Table 3, the results of this analysis show that $\mathrm{D}_{\text {rate }}$ increases with both $\mathrm{V}_{\mathrm{T}}(\mathrm{p}<0.001)$ and specific airway resistance $(\mathrm{p}<$ 0.001).

An index of airway deposition, $\mathrm{C} / \mathrm{P}_{0}$ ratios were slightly increased in the COPD patients relative to the healthy subjects (COPD, $1.11 \pm 0.10$; healthy, $1.01 \pm 0.11, \mathrm{p}=0.05$ ). In COPD patients, but not in healthy subjects, $\mathrm{C} / \mathrm{P}_{24}$ ratios were significantly lower than $\mathrm{C} / \mathrm{P}_{0}(\mathrm{p}=0.003)$. The $\mathrm{C} / \mathrm{P}_{24}$ ratios do not differ significantly between the healthy subjects and COPD subjects. The $C / \mathrm{P}_{0}$ in COPD patients was the only $\mathrm{C} / \mathrm{P}$ ratio that was significantly different from one $(\mathrm{p}=0.007)$. $\mathrm{C} / \mathrm{P}$ ratios were not correlated with lung function either within or across groups.

Pulmonary particle retention through 2 hours after inhalation for the COPD patients and healthy subjects is illustrated in Figure 5. Statistically, there was no difference in the 2-hour clearance curves between the COPD patients and the healthy subjects. However, a tendency for slower clearance in the COPD patients than healthy subjects could be observed. As illustrated in Figure 6, there was also an insignificant tendency for greater 24-hour retention (uncorrected and corrected for isotope leaching from particles) in the COPD patients relative to the healthy subjects. The 24-hour retention, measured at $23 \pm 2$ hours after inhalation, was $64 \pm 5 \%$ in healthy subjects and $67 \pm 4 \%$ in COPD patients $(\mathrm{p}=\mathrm{NS})$. Not differing between groups, the in vitro leaching of isotope from particles in saline was $23 \pm 4 \%$ after $23 \pm 2$ hours in solution. The 24 -hour retention after correction for this leaching was $84 \pm 9 \%$ in healthy subjects and $87 \pm$ $8 \%$ in COPD patients ( $\mathrm{p}=\mathrm{NS}$ ). This leaching correction was applied only to the 24-hour retention data and not to the 2-hour clearance curves.

No accumulation of particles in the liver ROI was observed.

TABLE 2. AVERAGE DEPOSITION (AIRWAYS AND TOTAL) AND BREATHING PATTERNS GROUPED BY DISEASE STATUS

\begin{tabular}{|c|c|c|c|c|}
\hline & \multirow[b]{2}{*}{$\begin{array}{l}\text { Healthy Subjects } \\
\qquad(3 M, 6 F)\end{array}$} & \multicolumn{3}{|c|}{ COPD Patients } \\
\hline & & $\begin{array}{l}\text { All Patients } \\
(7 M, 3 F)\end{array}$ & $\begin{array}{l}\text { Bronchitic Patients } \\
\text { (5 } M, 2 F)\end{array}$ & $\begin{array}{c}\text { Emphysemic Patients } \\
\qquad(2 M, 1 F)\end{array}$ \\
\hline DF, \% & $54 \pm 9^{\ddagger}$ & $62 \pm 12$ & $67 \pm 8^{*}$ & $48 \pm 8^{\dagger}$ \\
\hline$D_{\text {rate, }} \mu \mathrm{g} / \mathrm{hr}$ & $1.88 \pm 0.38$ & $2.90 \pm 1.02^{*}$ & $2.77 \pm 0.48^{*}$ & $3.20 \pm 1.94$ \\
\hline $\mathrm{C} / \mathrm{P}_{0}$ & $1.01 \pm 0.11$ & $1.11 \pm 0.10^{*}$ & $1.13 \pm 0.10^{*}$ & $1.06 \pm 0.11$ \\
\hline $\mathrm{C} / \mathrm{P}_{24}$ & $0.92 \pm 0.13$ & $1.00 \pm 0.13^{\S}$ & $1.04 \pm 0.10^{\S}$ & $0.90 \pm 0.14$ \\
\hline $\mathrm{V}_{\mathrm{T}}, \mathrm{ml}$ & $391 \pm 92$ & $621 \pm 322$ & $657 \pm 333^{*}$ & $537 \pm 344$ \\
\hline $\mathrm{T}_{\text {insp, }} \mathrm{s}$ & $2.02 \pm 0.24$ & $2.34 \pm 0.87$ & $2.73 \pm 0.74^{*}$ & $1.44 \pm 0.17^{\star \dagger}$ \\
\hline $\mathrm{V}_{\min }, \mathrm{L} / \mathrm{min}$ & $5.83 \pm 1.36$ & $8.13 \pm 3.74$ & $6.93 \pm 1.65$ & $10.9 \pm 6.2^{*}$ \\
\hline
\end{tabular}

Definition of abbreviations: $C O P D=$ chronic obstructive pulmonary disease; $C / P_{0}$ and $C / P_{24}=$ central-to-peripheral ratio initially and at 24 hours, respectively; $\mathrm{DF}=$ particle deposition fraction in the lung; $\mathrm{D}_{\text {rate }}=$ deposition rate a constant $10 \mu \mathrm{g} / \mathrm{m}^{3} \mathrm{exposure}$ to the experimental aerosol; $\mathrm{T}_{\text {insp }}=$ average inspiratory time during aerosol inhalation; $\mathrm{V}_{\min }=$ minute ventilation; $\mathrm{V}_{\mathrm{T}}=$ tidal volume during aerosol inhalation.

* Significantly different from healthy subjects $(p \leqslant 0.05)$.

$\dagger$ Significantly different from bronchitic subjects $(p<0.02)$.

₹ DF datum not available for one healthy male subject.

$\S$ Significantly different from $C / P_{0}$ by paired $t$ test $(p<0.03)$.

Values are means \pm SD. 
TABLE 3. BEST REGRESSION MODELS FOR PARTICLE DEPOSITION FRACTION IN THE LUNG AND DEPOSITION RATE IN ALL SUBJECTS

\begin{tabular}{llcr}
\hline Dependent Variable & Independent Variable & Coefficient & $\mathrm{p}$ Value \\
\hline $\mathrm{DF}, \%$ & $\mathrm{FEF}_{25-75}$ Ips & -7.54 & 0.0003 \\
& $\mathrm{DL}_{\mathrm{CO}} / \mathrm{VA}_{\mathrm{A}}, \%$ predicted & 30.9 & 0.0012 \\
& Constant, \% & 40.6 & $<0.0001$ \\
& $\quad$ (Overall regression, $\left.\mathrm{R}^{2}=0.62, \mathrm{p}=0.0007\right)$ \\
$\mathrm{D}_{\text {rate, }} \mu \mathrm{g} / \mathrm{hr}$ & $\mathrm{VT}, \mathrm{L}$ & 1.770 & 0.0008 \\
& sRaw, $\mathrm{cm} \mathrm{H} \mathrm{O} \mathrm{s}$ & 0.044 & 0.0002 \\
& Constant, $\mu \mathrm{g} / \mathrm{hr}$ & 1.015 & 0.0005 \\
& (Overall regression, $\left.\mathrm{R}^{2}=0.81, \mathrm{p}<0.0001\right)$ \\
\hline
\end{tabular}

Definition of abbreviations: $\mathrm{DF}=$ particle deposition fraction in the lung; $\mathrm{D}_{\text {rate }}=$ deposition rate a constant $10 \mu \mathrm{g} / \mathrm{m}^{3}$ exposure to the experimental aerosol; $\mathrm{DLCO}_{\mathrm{CO}}$ $\mathrm{V}_{\mathrm{A}}=$ diffusing capacity normalized to lung volume, predictive equations Burrows and colleagues (33); sRaw = specific airway resistance; $\mathrm{V}_{\mathrm{T}}=$ tidal volume during aerosol inhalation.

The fraction of activity in the liver ROI was analyzed at 10minute increments throughout the 2-hour period after inhalation. On average across all subjects, the fraction of activity in the liver ROI was $1.3 \pm 1.2 \%$ initially, $1.4 \pm 0.8 \%$ at 1 hour, and $1.3 \pm 0.8 \%$ at 2 hours after inhalation. No significant deviation in the fraction of activity in the liver ROI during the 2-hour period was observed in COPD patients, healthy subjects, nor across all subjects. There was no significant difference in the fraction of activity in the liver ROI between the COPD patients and healthy subjects.

\section{DISCUSSION}

We investigated the deposition and clearance of an ultrafine aerosol (CMD, $33 \pm 2 \mathrm{~nm}$; AMD, $61 \pm 4 \mathrm{~nm})$ in a group of 10 COPD patients (45-70 years old) with moderate to severe airways obstruction and 9 healthy volunteers (40-67 years old). We found no difference in particle clearance rates between the healthy subjects and COPD patients, nor were we able to detect the accumulation of particles in the vicinity of the liver. Based on diffusing capacity, the COPD patients were subdivided into groups of seven bronchitic patients and three emphysemic patients. We found an increased particle DF in the bronchitic patients relative to the healthy subjects and emphysemic patients (Table 2); however, when deposition was expressed as a $\mathrm{D}_{\text {rate, }}$, it was observed that the $D_{\text {rate }}$ in emphysemic patients actually tended to be increased relative to the bronchitic patients. Moreover, larger relative increases in $\mathrm{D}_{\text {rate }}(54 \%)$ were observed than for DF $(15 \%)$ in the COPD patients compared with healthy subjects. This is due to the fact that, at rest, the COPD patients breathe spontaneously with a higher minute ventilation than the healthy individuals (24).

A comparison of our results with prior studies is possible for the DF data in healthy subjects, and to a lesser extent, in the COPD patients. However, even comparisons of DF in healthy individuals are complicated because of differing methods. For example, decreasing particle size below $100 \mathrm{~nm}$ and increasing residence time will effect an increase in $\operatorname{DF}(9,10,12,13)$. Theoretically, there is also an effect of polydisperse versus monodisperse aerosol inhalation on DF, such that increasing polydispersity below approximately $40 \mathrm{~nm}$ should decrease $\mathrm{DF}$, whereas above this particle size, it should cause an increase in DF (34). Finally, age effects on ultrafine particle deposition are unknown. With these issues noted, the data of a few studies are discussed later here.

Jaques and Kim (12) conducted an extensive particle deposition study in 22 young healthy adults ( 11 females and 11 males) with six breathing patterns and a CMD of 40,60, 80, and 100 $\mathrm{nm}$. For the breathing pattern of $\mathrm{V}_{\mathrm{T}}=500 \mathrm{ml}$ and $\mathrm{f}=15 \mathrm{~min}^{-1}$ (the most comparable to that of our healthy subjects) and a CMD of $40,60,80$, and $100 \mathrm{~nm}$, they found the DF of $44 \pm 7 \%$, $35 \pm 5 \%, 30 \pm 5 \%$, and $26 \pm 4 \%$, respectively. Schiller and colleagues (10) also provided a large dataset for a range of particle sizes ( 5 to $200 \mathrm{~nm}$ ) and 11 different breathing patterns, but only in 4 healthy male subjects. These investigators found slightly lower DF than observed in male subjects by Jaques and Kim (12). For polydisperse carbon particle aggregates $(\mathrm{CMD}=$ $26 \mathrm{~nm}, \sigma_{\mathrm{g}}=2.3$ ), Frampton and colleagues (35) reported a DF of $66 \pm 12 \%$ by count and $58 \pm 14 \%$ by mass in 12 healthy young adults ( 6 females and 6 males) spontaneously breathing on a mouthpiece. As a technical note, the DF data reported by Jaques and Kim (12) and by Schiller and associates (10) were for specific monodisperse particle sizes, as such there should be no differences in DF determined by count versus mass. Our DF data are for a polydisperse aerosol and are based on the amount of radioaerosol collected on filters making them similar to a DF determined by a change in mass. Although in the range of other studies, our methods and results are most similar to that of Frampton and colleagues (35), with a DF of $54 \pm 9 \%$ for a polydisperse aerosol $\left(\mathrm{CMD}, 33 \mathrm{~nm} ; \sigma_{\mathrm{g}}=1.7\right)$ inhaled with a $\mathrm{VT}_{\mathrm{T}}=391 \mathrm{ml}$ and $\mathrm{f}=15 \mathrm{~min}^{-1}$ by nine healthy subjects.

Only one prior study's data are available for comparison of DF results in patients. For the CMD of 20, 40, and $60 \mathrm{~nm}$ respired at $\mathrm{VT}_{\mathrm{T}}=1000 \mathrm{ml}$ and $\mathrm{f}=12 \mathrm{~min}^{-1}$, Anderson and colleagues (11) reported the DF (respective to CMD) of $47 \pm 9 \%, 38 \pm$ $6 \%, 33 \pm 9 \%$ in 10 healthy subjects and $54 \pm 4 \%, 46 \pm 4 \%$, $45 \pm 4 \%$ in 5 patients with obstructive lung disease. These DF data are lower than we have observed. Anderson and colleagues' DF data for healthy subjects are also lower than reported by Jaques and Kim (12) and Schiller and colleagues (10). However, Anderson and colleagues' relative increases in DF due to obstructive lung disease are 15,21 , and $36 \%$ for the respective CMD of 20, 40, and $80 \mathrm{~nm}$. Similarly, for our 33-nm CMD aerosol, we found DF increased by $15 \%$ in COPD as a whole and by $26 \%$ in the bronchitic patients relative to the healthy subjects. Anderson and colleagues (11) also reported that DF was not correlated with any spirometric or lung volume parameters in the five obstructive lung disease patients. Possibly due to our larger sample size, we found correlations between lung function and DF in the COPD patients.

Unlike most prior studies of particle deposition, the subjects in our study respired aerosol at their natural sedentary breathing pattern, whereas other studies typically have all subjects breathe at the same fixed conditions. Although this disparity in method complicates comparisons between subject groups and between studies, it is advantageous in that data may be derived that are applicable to real-world exposure-dose scenarios. Accordingly, $\mathrm{D}_{\text {rate }}$ were calculated and provide an estimate of the ultrafine particle mass that would be deposited per hour in the lungs of subjects while at rest. We found that the COPD patients had a $54 \%$ greater $\mathrm{D}_{\text {rate }}$ than did healthy subjects $(\mathrm{p}=0.02)$. Based on DF alone, these patients had an increase of only $15 \%$ relative to healthy subjects $(\mathrm{p}=\mathrm{NS})$. Interestingly, the emphysemic patients appeared to have $11 \%$ less deposition than the healthy subjects based on their average DF, whereas their $\mathrm{D}_{\text {rate }}$ showed a $70 \%$ average increase in deposition relative to the healthy subjects. Again, this is due to the fact that, at rest, these patients tended to breathe spontaneously with a higher minute ventilation than the healthy individuals. These findings are consistent with Bennett and colleagues (24), who found greater increases in the $\mathrm{D}_{\text {rate }}$ than for the DF in COPD patients relative to healthy subjects for a fine 2- $\mu \mathrm{m}$ mass median aerodynamic diameter aerosol. 
Particle deposition within the airways was also increased in COPD patients relative to the healthy subjects. An index of excess airways deposition, $\mathrm{C} / \mathrm{P}_{0}$ ratios were significantly $(\mathrm{p}=$ 0.05 ) increased in the COPD patients relative to healthy subjects $(1.11 \pm 0.10$ versus $1.01 \pm 0.11)$. The increased $\mathrm{C} / \mathrm{P}_{0}$ ratios in COPD patients could reflect enhanced airways deposition of ultrafine particles by turbulent diffusion caused by airway obstruction, although no significant correlations were observed between $\mathrm{C} / \mathrm{P}_{0}$ ratios and spirometry to support this supposition. In addition to their increased $\mathrm{D}_{\text {rate }}$, the increased $\mathrm{C} / \mathrm{P}_{0}$ ratios show the potential for greater particle doses to the airways of patients relative to healthy individuals. It should be noted, however, that the "increased" $\mathrm{C} / \mathrm{P}_{0}$ ratios that we observed in COPD patients reflect far less airways deposition than is found for coarse particles, which deposit by inertial impaction. For example, Bennett and Zeman (36) found a $\mathrm{C} / \mathrm{P}_{0}$ of 2.2 in $12 \mathrm{COPD}$ patients $\left(\mathrm{FEV}_{1} /\right.$ $\mathrm{FVC}=55 \%$ ) who respired a $5-\mu \mathrm{m}$ mass median aerodynamic diameter aerosol at $\mathrm{V}_{\mathrm{T}}=500 \mathrm{ml}$ and $\mathrm{f}=30 \mathrm{~min}^{-1}$. At 24 hours after inhalation, those patients had a mean retention of approximately $13 \%$, suggesting that $87 \%$ of the particles were deposited within and subsequently removed from the airways via mucociliary clearance. Quite the opposite, we found a 24hour retention of $87 \pm 8 \%$ in COPD patients after correction of isotope leaching. Despite the statistically increased $\mathrm{C} / \mathrm{P}_{0}$ ratios in our COPD patients, comparison with the data for larger particles illustrates the small degree of ultrafine particle deposition in the bronchial airways.

Pulmonary particle clearance was similar between the COPD patients and healthy subjects. There was an insignificant tendency for greater retention in the COPD patients relative to the healthy subjects during the 2-hour period after deposition, which was also observed at 24 hours. Retention at 24 hours after deposition was corrected for $23 \%$ isotope leaching from particles in saline. The leaching characteristics of the isotope did not differ between the healthy subjects and COPD patients. On average, this leaching correction increased 24-hour retention from $66 \pm$ $5 \%$ to $85 \pm 8 \%$. This in vitro method has been used by others and provides a conservative estimate of leaching, that is, greater technetium-99m dissolution from particles, relative to in vitro leaching in simulated lung fluid (37) or in vivo leaching after radiolabeled aerosol inhalation (38). Hence, $85 \pm 8 \%$ is likely an upper bound for the expected particle retention at 24 hours after deposition. It is not expected that isotope leaching would have caused differences between the healthy subjects and COPD patients. Smokers have been shown to have increased lung epithelial permeability as demonstrated by increased clearance rates of inhaled soluble compounds (39). Hence, an effect of leaching might have been to increase rapid (less than 20 minutes) clearance in the COPD patients relative to the healthy subjects. Referring to Figure 5, clearance rates were indistinguishable until 30 minutes after inhalation. The pulmonary clearance kinetics of the experimental aerosol appear quite similar for the COPD patients and healthy subjects.

Based on similar clearance kinetics and only modestly increased $C / \mathrm{P}_{0}$ ratios, relative to healthy subjects, it is likely that the increased $\mathrm{D}_{\text {rate }}$ in COPD patients primarily affects the parenchymal lung. Assuming a uniform ventilation distribution in the lung, the parenchymal surface dose in COPD patients is $54 \%$ greater than in healthy subjects. However, in COPD patients, the assumption of uniform ventilation is questionable. In patients with COPD, the time constants of some diseased regions are thought to be in excess of 3 seconds, whereas healthy regions might be expected to have a time constant of the order of 0.1 seconds (40). This variability in regional time constants leads to the observation of slower and less uniform rates of air exchange in patients relative to healthy individuals (41), which may in turn affect regional particle deposition. Ultrafine particles may penetrate into poorly ventilated regions and then have enhanced deposition due to the long time constant of these regions. Increased particle deposition in poorly ventilated lung regions has been reported for aerosols in the 0.5 to $1.0 \mu \mathrm{m}$ size range and attributed to increased residence time in obstructed areas (42, 43). On the other hand, as ventilation is reduced to obstructed regions, healthier regions receive the balance of ventilation and associated particle exposure. To an extent, these phenomena have been observed in patients with mild-to-moderate asthma where large wedge-shaped regions of the lung were observed absent the deposition of fine particles (approximately $0.12 \mu \mathrm{m}$ diameter) (44). Whether ultrafine particle deposition is enhanced in poorly ventilated regions or shifted to healthy regions, the pattern of deposition is in all likelihood far less uniform in COPD patients than in the healthy subjects. As a first approximation of this effect, Miller and colleagues (45) assumed that a quarter of the parenchymal lung in COPD patients might receive all the deposition normally distributed across the full parenchymal lung. Applying this approximation and the observed $\mathrm{D}_{\text {rate }}$, the parenchymal lung tissues in COPD patients would receive a $600 \%$ greater dose than these tissues within a healthy individual. Such an increased surface dose in sensitive patients might be sufficient to elicit an inflammatory response with systemic effects such as those proposed by Seaton and colleagues (6).

Others have proposed that ultrafine particles elicit an effect by moving rapidly (within minutes after deposition) into circulation and accumulating in other organs such as the liver. We found no such accumulation of particles in the vicinity of the liver. On average across all subjects $(n=19)$, we observed $1.3 \pm$ $1.2 \%$ of the deposited activity in the liver ROI on the initial retention scan. This activity may be due to scatter from the lung and/or overlap of lung parenchyma in the liver ROI. The relative amount of activity in the liver ROI did not significantly deviate over the 2-hour period after inhalation. In contrast, Nemmar and colleagues $(20)$ reported that $8 \%(n=5)$ of deposited activity accumulated in the liver by 5 minutes after inhalation. They also observed the accumulation of $25 \%$ of the deposited activity in the bladder by 45 minutes with large unquantified amounts of activity in the thyroid, salivary glands, and stomach. Although not reported, their pulmonary retention at 45 minutes after inhalation must be on average less than $67 \%$ after accounting for activity in the liver and bladder. This contrasts sharply with the $91 \%$ average retention that we observed at 45 minutes. Prior studies have reported pulmonary retention at 45 minutes for Technegas, the aerosol used by Nemmar and associates (20). In contrast to Nemmar and colleagues (20), the Technegas pulmonary retention reported by Roth and associates (17) was $95 \%$ $(\mathrm{n}=3)$ and by Isawa and colleagues $(46)$ was $98 \%(\mathrm{n}=11)$.

The disparity in results between Nemmar and colleagues (20) and the results of our present study and prior studies using Technegas may be due to Pertechnegas contamination. Unlike Technegas, which is considered relatively stable in the lung, Pertechnegas is thought to be rapidly ionized to pertechnetate $\left(\mathrm{TcO}_{4}^{-}\right)$in the presence of moisture $(39,47,48)$. In fact, the pulmonary clearance kinetics of inhaled pertechnetate and Pertechnegas are statistically indistinguishable $(39,47)$. Technegas and Pertechnegas are produced by the same proprietary generator under differing atmospheres (Technegas, 100\% argon; Pertechnegas, $3 \%$ oxygen and $97 \%$ argon) $(16,39,47,49)$. The transition from Technegas to Pertechnegas occurs abruptly at an oxygen concentration of between $0.1 \%$ and $0.2 \%$ (49). Hence, minimal oxygen contamination within the generator can cause Pertechnegas contamination of Technegas. Even when produced under a $100 \%$ argon atmosphere, Technegas still has an immediately soluble fraction of approximately $20 \%$ (49). Xu and col- 
leagues (48) reported Pertechnegas contamination of Technegas in their clearance study of patients $(n=6)$ and healthy volunteers $(\mathrm{n}=5)$. These investigators noticed the contamination because of thyroid visualization and rapid clearance during the first 20 minutes after inhalation $(9.3 \pm 1.8$ minute halftime; $\mathrm{n}=11)$. The rapid clearance rates found by $\mathrm{Xu}$ and associates (48) are quite similar to the Pertechnegas half-times reported by Monaghan and colleagues (39) and Isawa and colleagues (47) in healthy subjects of $10.1 \pm 2.4$ minutes $(n=22)$ and $10.8 \pm$ 1.8 minutes $(\mathrm{n}=5)$, respectively. Interestingly, Monaghan and colleagues (39) provided a whole-body scan illustrating organ uptake of Pertechnegas, which appears remarkably similar to the whole-body scan from Nemmar and associates (20) with high amounts of activity evident in the bladder, stomach, thyroid, and salivary glands. Based on the organ uptake reported by Nemmar and colleagues (20) and rapid pulmonary clearance rates inferred from their findings, the bulk of the lung clearance that they observed was very likely that of pertechnetate ionized from Pertechnegas and not that of radiolabeled ultrafine particles.

We have found that patients with moderate to severe COPD have an increased $D_{\text {rate }}$ of $54 \%$ relative to healthy subjects. Some of this increased deposition occurs in the airways, although most likely occurs in the parenchymal lung. Given that these patients have heterogeneous ventilation within their lungs, they may receive a tissue dose to the parenchymal lung that is many times that occurring in the healthy lung. We found no evidence of the rapid pulmonary clearance of these insoluble, carbon ultrafine particles into the circulation. The increased tissue dose received by COPD patients may contribute to systemic effects as a result of an exacerbation of their airway inflammation and cytokine release into circulation, but not the rapid movement of significant number of insoluble particles into the circulation.

\section{References}

1. Dockery DW, Pope CA, Xu X, Spengler JD, Ware JH, Fay ME, Ferris BG, Speizer FE. An association between air pollution and mortality in six US cities. $N$ Engl J Med 1993;329:1753-1759.

2. Pope CA, Dockery DW, Schwartz J. Review of epidemiological evidence of health effects of particulate air pollution. Inhal Toxicol 1995;7:1-18.

3. Ferin J, Oberdorster G, Penny DP. Pulmonary retention of ultrafine and fine particle in rats. Am J Respir Cell Mol Biol 1992;6:535-542.

4. Ferin J. Pulmonary retention and clearance of particles. Toxicol Letters 1994:72:121-125.

5. Churg A. The uptake of mineral particles by pulmonary epithelial cell. Am J Respir Crit Care Med 1996;154:1124-1140.

6. Seaton A, MacNee W, Donaldson K, Godden D. Particulate air pollution and acute health effects. Lancet 1995;345:176-178.

7. Peters A, Doring A, Wichmann HE, Koenig W. Increased plasma viscosity during an air pollution episode: a link to mortality? Lancet 1997; 349:1582-1587.

8. Peters A, Wichmann HE, Tuch T, Heinrich J, Heyder J. Respiratory effects are associated with the number of ultrafine particles. Am J Respir Crit Care Med 1997:155:1376-1383.

9. Wilson FJ Jr, Hiller FC, Wilson JD, Bone RC. Quantitative deposition of ultrafine stable particles in the human respiratory tract. $J$ Appl Physiol 1985;58:223-229.

10. Schiller CF, Gebhart J, Heyder J, Rudolf G, Stahlhofen W. Deposition of monodisperse insoluble aerosol particles in the 0.005 to $0.2 \mu \mathrm{m}$ size range within the human respiratory tract. Ann Occup Hyg 1988;32 (Suppl. 1):41-49.

11. Anderson PJ, Wilson JD, Hiller FC. Respiratory tract deposition of ultrafine particles in subjects with obstructive or restrictive lung disease. Chest 1990;97:1115-1120.

12. Jaques PA, Kim CS. Measurement of total lung deposition of inhaled ultrafine particles in healthy men and women. Inhal Toxicol 2000;12: 715-731.

13. Kim CS, Jaques PA. Respiratory dose of inhaled ultrafine particles in healthy adults. Philos Trans $R$ Soc Lond A 2000;358:2693-2705.

14. Roth C, Scheuch G, Stahlhofen W. Clearance measurements with radio- actively labelled ultrafine particles. Ann Occup Hyg 1994;38(Suppl. 1):101-106.

15. Lemb M, Oei TH, Eifert H, Gunther B. Technegas: a study of particle structure, size and distribution. Eur J Nucl Med 1993;20:576-579.

16. Lloyd JJ, Shields RA, Taylor CJ, Lawson RS, James JM, Testra HJ. Technegas and Pertechnegas particle size and distribution. Eur J Nucl Med 1995;22:473-476.

17. Roth C, Kreyling WG, Scheuch G, Busch B, Stahlhofen W. Deposition and clearance of fine particles in the human respiratory tract. Ann Occup Hyg 1997;41(Suppl. 1):503-508.

18. Burch WM, Sullivan PJ, McLaren CJ. Technegas: a new ventilation agent for lung scanning. Nucl Med Commun 1986;7:865-871.

19. Pellegrino R, Biggi A, Papaleo A, Camuzzini G, Rodarte JR, Brusasco V. Regional expiratory flow limitation studied with Technegas in asthma. J Appl Physiol 2001;91:2190-2198.

20. Nemmar A, Hoet PHM, Vanquickenborne B, Dinsdale D, Thomeer M, Hoylaerts MF, Vanbilloen H, Mortelmans L, Nemery B. Passage of inhaled particles into the blood circulation in humans. Circulation 2002:105:411-414.

21. Stahlhofen W, Rudolf G, James AC. Intercomparison of experimental regional aerosol deposition data. J Aerosol Med 1989;2:285-308.

22. Brown JS, Gerrity TR, Bennett WD. Effect of ventilation distribution on aerosol bolus dispersion and recovery. J Appl Physiol 1988;85:21122117

23. Brown JS, Kim CS, Reist PC, Zeman KL, Bennett WD. Generation of radiolabeled "soot-like" ultrafine aerosols suitable for use in human inhalation studies. Aerosol Sci Technol 2000;32:325-337.

24. Bennett WD, Zeman KL, Kim C, Mascarella J. Enhanced deposition of fine particles in COPD patients spontaneously breathing at rest. Inhal Toxicol 1997;19:1-14.

25. Sinclair D, Hoopes GS. A novel form of diffusion battery. Am Ind Hyg Assoc J 1975;36:39-42.

26. Brown JS, Zeman KL, Bennett WD. Regional deposition of coarse particles and ventilation distribution in patients with cystic fibrosis. J Aerosol Med 2001;14:443-454.

27. Smaldone GC, Perry RJ, Bennett WD, Messina MS, Zwang J, Ilowite L. Interpretation of " 24 hour lung retention" in studies of mucociliary clearance. J Aerosol Med 1988;1:11-20.

28. Ilowite J, Smaldone GC, Perry RJ, Bennett WD, Foster WM. Relationship between tracheobronchial particle clearance rates and sites of initial deposition in man. Arch Environ Health 1989;44:267-273.

29. Smaldone GC, Foster WM, O'Riordan TC, Messina MS, Perry RJ, Langenback EG. Regional impairment of mucociliary clearance in chronic obstructive pulmonary disease. Chest 1993;103:1390-1396.

30. Littel RC, Milliken GA, Stroup WW, Wolfinger RD. SAS system for mixed models. Cary, NC: SAS Institute; 1996.

31. Pinheiro JC, Bates DM. Mixed-effects models in S and S-plus. New York: Springer; 2000.

32. Knudson RJ, Lebowitz MD, Holberg CJ, Burrows B. Changes in the normal maximal expiratory flow-volume curve with growth and aging. Am Rev Respir Dis 1983;127:725-734.

33. Burrows B, Kasik JE, Niden AH, Barclay WR. Clinical usefulness of the single-breath pulmonary diffusing capacity test. Am Rev Respir Dis 1961;84:789-806.

34. Diu CK, Yu CP. Respiratory tract deposition of polydisperse aerosols in humans. Am Ind Hyg Assoc J 1983;44:62-65.

35. Frampton MW, Chalupa D, Morrow PE, Gibb FR, Oberdorster G, Boscia J, Speers DM, Utell MJ. Deposition of inhaled ultrafine carbon particles in resting healthy nonsmoking adults [abstract]. Am J Respir Crit Care Med 2000;161:A257.

36. Bennett WD, Zeman KL. Effect of enhanced supramaximal flows on cough clearance. J Appl Physiol 1994;77:1577-1583.

37. Wales KA, Petrow H, Yeates DB. Production of ${ }^{99 \mathrm{~m}} \mathrm{Tc}$-labeled iron oxide aerosols for human lung deposition and clearance studies. Int J Appl Radiat Isot 1980;31:689-694.

38. Scheuch G, Miller W, Sommerer K. Insoluble $99 \mathrm{mTc}$ labelled iron oxide for clearance studies. 17th Annual American Association for Aerosol Research Conference. Cincinnati, OH: American Association for Aerosol Research; 1998. p. 268.

39. Monaghan P, Provan I, Murray C, Mackey DWJ, Van der Wall H, Walker BM, Jones PD. An improved radionuclide technique for the detection of altered pulmonary permeability. J Nucl Med 1991;32:1945-1949.

40. Mead J. Contribution of compliance of airways to frequency-dependent behavior of lungs. J Appl Physiol 1969;26:670-673.

41. Suga K, Nishigauchi K, Kume N, Koike S, Takano K, Matsunaga N. Regional ventilation evaluation using dynamic SPET imaging of xe- 
non-133 washout in obstructive lung disease: an initial study. Eur $J$ Nucl Med 1995;22:220-226.

42. Trajan M, Logus JW, Enns EG, Man SFP. Relationship between regional ventilation and aerosol deposition in tidal breathing. Am Rev Respir Dis 1984:130:64-70.

43. Susskind H, Brill AB, Harold WH. Quantitative comparison of regional distributions of inhaled Tc-99m DTPA aerosol and $\mathrm{Kr}-81 \mathrm{~m}$ Gas in coal miners' lungs. Am J Physiol Imaging 1986;1:67-76.

44. King GG, Eberl S, Salome CM, Young IH, Woolcock AJ. Differences in airway closure between normal and asthmatic subjects measured with single-photon emission computed tomography and Technegas. Am J Respir Crit Care Med 1998;158:1900-1906.

45. Miller FJ, Anjilvel S, Menache MG, Asgharian B, Gerrity TR. Dosimetric Issues relating to particle toxicity. Inhal Toxicol 1995;7:615-632.

46. Isawa T, Teshima T, Anazawa Y, Miki M, Motomiya M. Technegas for inhalation lung imaging. Nucl Med Commun 1991;12:47-55.

47. Isawa T, Teshima T, Anazawa Y, Miki M, Mahmud AM. Inhalation of pertechnegas: similar clearance from the lung to that of inhaled pertechnetate aerosol. Nucl Med Commun 1995;16:741-746.

48. Xu JH, Moonen M, Johansson A, Bake B. Dynamics of "Technegas" deposited in the lung. Nucl Med Commun 2001;22:383-387.
49. Scalzetti EM, Gagne GM. The transition from Technegas to Pertechnegas. J Nucl Med 1995;36:267-269.

\section{APPENDIX}

The effect of apparatus dead space on DF data was investigated using filters (BB-5OT; Pall Biomedical, Fajardo, Puerto Rico) and a ventilator (Model 608; Harvard Apparatus, Holliston, MA). Referring to Figure 1, Filter 1 was placed as illustrated to capture exhaled aerosol. To simulate an individual with a DF of $100 \%$ breathing on the apparatus, a second filter (same type as Filter 1) was placed on the mouthpiece and attached to the ventilator. Twelve trials were conducted with VT ranging from 330 to $1050 \mathrm{ml}$. These trials showed a tendency to underestimate DF with decreasing VT. The DF from these simulated maneuvers $\left(\mathrm{DF}_{\text {sim }}\right)$, fit by linear regression as a function of $\mathrm{VT}_{\mathrm{T}}$, showed $\mathrm{DF}_{\text {sim }}=0.73+0.20 \mathrm{VT}_{\mathrm{T}}(r=0.93, \mathrm{p}<0.001)$. Experimentally, a subject's DF was corrected for dead space by division of the predicted $\mathrm{DF}_{\text {sim }}$ at the subject's VT during the aerosol inhalation. On average, the $\mathrm{DF}_{\text {sim }}$ applied as a correction factor to DF data was $0.83 \pm 0.05$. 